\title{
DWA NIEDRUKOWANE DOKUMENTY DOTYCZĄCE RACIBORSKIEJ DOMINIKANKI AGNIESZKI
}

Klasztor dominikanek w Raciborzu został ufundowany 1 października 1299 r. przez księcia raciborskiego Przemysła i był drugim dominikańskim domem żeńskim na Śląsku, a trzecim na ziemiach polskich. Wcześniej powstały klasztory dominikanek w Poznaniu (przed 1282 r.) i Wrocławiu (1290-1292 r.) $)^{1}$. Dzieje raciborskiego klasztoru sióstr zakonu św. Dominika od zarania związane są z księżniczką raciborską Eufemią, córką fundatora, która wstąpiła do niego 9 kwietnia 1313 r., a w latach 1341-1346 i 1349-1359 piastowała w nim urząd przeoryszy. Cieszyła się ona powszechnym szacunkiem i była wzorem dla wielu pokoleń zakonnic, które otaczały ją kultem² .

${ }^{1}$ J. K ł o c z o w s k i, Dominikanie polscy na Ślasku w XIII-XIV wieku, Lublin 1956, s. 307; P. S t e f a n i a k, Najstarszy polski klasztor dominikanek klauzurowych i jego mieszkanki, „Kronika Miasta Poznania” t. 3, 2004, s. 120-130; T e n ż e, Z dziejów klasztoru Świętego Ducha mniszek dominikańskich w Raciborzu (1299-1810), „Nasza Przeszłość" t. 112, 2009, s. 181-206; A. T a r n a s - T o m c z y k, Uposażenie fundacyjne śląskich klasztorów żeńskich do połowy XIV wieku, [w:] Sanctimoniales. Zakony żeńskie w Polsce i Europie Środkowej (do przełomu XVIII i XIX wieku), red. A. Radzi miński, D. K a r c zews ki, Z. Zy g lew s ki, Bydgoszcz-Toruń 2010, s. 224-226.

${ }^{2}$ Szerzej na temat Eufemii raciborskiej i jej kultu, zob. B. S u c h oń, Ofka, Eufemia, Domitilla, [w:] Hagiografia Polska. Stownik bio-bibliograficzny, t. 2, red. R. G u s t a w, Poznań 1972, s. 160-171; F. W o l n i k, Świątobliwa Eufemia (Ofka) - życie i rozwój jej kultu, [w:] Świętość na ziemi raciborskiej, red. T e n ż e, Opole 2009, Sympozja, t. 76, s. 23-43; P. S t e f a n i a k, Błogosławiona Eufemia Piastówna OP (1299-1359) $w$ świetle trzech najstarszych żywotów oraz źródel a także literatury, „Nasza Przeszłość” t. 111, 2009, s. 159-191; G. K ubli n, Średniowieczne $i$ nowożytne testimonia sanctitatis Eufemii raciborskiej (zm. 1359), „Folia Historica Cracoviensia” t. 19, 2013, s. 73-90; T e n ż e, Świątobliwa Eufemia raciborska (†17 I 1359), Opole 2013; Tenże, XVII-wieczny żywot księżniczki raciborskiej Eufemii $w$ zbiorach Archiwum Państwowego we Wrocławiu, Opole 2016, Studia i źródła do dziejów dominikanów

„Nasza Przeszłość”t. 132: 2019, s. 67-77. 
Nie można wskazać, ile zakonnic, oprócz Eufemii, przebywało w raciborskim klasztorze w średniowieczu. Nie zachował się żaden nekrolog tego klasztoru ani matrykuła ślubów zakonnych. Dla porównania wiadomo, że 6 kwietnia 1333 r. została ustalona liczba sióstr (numerus clausus) klasztoru dominikanek we Wrocławiu na 60 panien, a 7 lutego 1337 r. została ona powiększona o kolejnych 10 osób $^{3}$. W przypadku raciborskich dominikanek można jedynie podać imiona niektórych zakonnic, które zachowały się w materiałach źródłowych. Zadania rozpoznania składu osobowego klasztoru dominikanek w Raciborzu w średniowieczu podjął się Antoni Barciak. Zauważył on, że w tymże konwencie były córki książąt, rycerzy, szlachciców i mieszczan ${ }^{4}$.

Do raciborskich dominikanek epoki średniowiecza pochodzaccych z mieszczaństwa należała Agnieszka. Była ona córką rzemieślnika Konrada Sleussera z Nysy. Znana jest jedynie z dwóch dokumentów, dotąd niedrukowanych, przechowywanych w Archiwum Państwowym w Opolu. Nie są one włączone do zespołu nr 3151: Klasztor ss. Dominikanek $p w$. Św. Ducha $w$ Raciborzu, lecz umieszczone w zespole nr 1242: Akta miasta Brzegu. Podstawowe informacje o nich znajdują się w pierwszym tomie wydawnictwa Regesty dokumentów przechowywanych na Górnym Ślasku ${ }^{5}$. Chodzi o pismo raciborskiej przeoryszy Streczki wystawione 29 sierpnia 1365 r. w Raciborzu i o dokument biskupa wrocławskiego Przecława wydany 13 stycznia 1366 r. w Otmuchowie. Niestety, tylko pismo Streczki ocalało w oryginale jako pergamin o wymiarach 270 x $150+15$ mm. Dokument biskupa Przecława zachował się jako papierowa kopia, sporządzona prawdopodobnie w XIX w.,

i dominikanek w Raciborzu, t. 1; T e nże, Dzieło Reginalda Brauna z 1741 roku poświęcone księżniczce raciborskiej Eufemii, Opole 2018, Studia i źródła do dziejów dominikanów i dominikanek w Raciborzu, t. 2.

3 Regesten zur schlesischen Geschichte 1327-1333, t. 6, wyd. C. Grünhagen, K. Wutke, Breslau 1903, Codex diplomaticus Silesiae, t. 22, nr 5215, s. 183; Regesten zur schlesischen Geschichte 1334-1337, t. 7, wyd. K. Wutke, Breslau 1923, Codex diplomaticus Silesiae, t. 29, nr 5835, s. 139-140; Breslauer Urkundenbuch, wyd. G. Korn, Breslau 1870, nr 153, s. 137; J. Kł o c z o w s k i, $d z$. cyt., s. 263; K. K a c z m a r e k, Przyczynek do badań nad prozopografia konwentu dominikanek wrocławskich $w$ średniowieczu, [w:] Sanctimoniales, dz. cyt., s. 349.

${ }^{4}$ A. B a r c i a k, Skład osobowy klasztoru dominikanek raciborskich $w$ średniowieczu, [w:] Sanctimoniales, dz. cyt., s. 333-341.

${ }^{5}$ Regesty dokumentów przechowywanych na Górnym Śląsku, t. 1, red. A. B a r c i a k, K. M ü 11 e r, Wrocław-Opava 2004, nr 86 i 89, s. 51-52. 
o wymiarach 125 x $355 \mathrm{~mm}$. Trzeba dodać, że w trakcie opracowywania pierwszego tomu Regestów dokumentów przechowywanych na Górnym Śląsku oba dokumenty miały przydzieloną tymczasową sygnaturę, a pierwszy z nich znajdował się w zespole nr 108: Cechy miasta Brzegu. Aktualnie oba dokumenty są przechowywane w zespole nr 1242: Akta miasta Brzegu, przy czym pierwszy z nich został oznaczony sygnatura 8309, a drugi 14. Zanim dokumenty trafiły do Opola, były przechowywane w Muzeum Piastowskim w Brzegu pod sygnaturami: 686 i 557, które widnieją na odwrocie przedstawianych dokumentów. W $1870 \mathrm{r}$. dokument z 29 sierpnia 1365 r. znajdował się w Archiwum Miejskim (Stadtarchiv) w Brzegu oznaczony sygnaturą V. 5, która do dziś pozostała na odwrocie dokumentu ${ }^{6}$.

Dokument przeoryszy Streczki został zaopatrzony w dwie pieczęcie na pergaminowym pasku. Pierwsza, znacznie większa, w kształcie elipsy, jest pieczęcią raciborskiego konwentu sióstr. Przedstawia ona Boga Ojca trzymającego krucyfiks. W otoku napis: S. CONVENTVS SORORVM IN RATIBOR ORD. PREDICA ${ }^{7}$. Druga mniejsza, okrągła, jest pieczęcią miasta Brzegu. Przedstawia tarczę, na której widnieją trzy kotwice zakończone hakami i połączone centralnie położonym pierścieniem. W otoku napis: SIGILLUM BURIENSIUM D. BRIGA ${ }^{8}$.

Wzmiankowana przeorysza Streczka znana jest jedynie z przedstawianego dokumentu, wydanego 29 sierpnia 1365 r. Przed nią na tym urzędzie pojawia się w źródłach księżniczka raciborska Eufemia (1349-1359) ${ }^{9}$, a po niej księżniczka opawsko-raciborska Eufemia (1375-1379), której pobyt w raciborskim klasztorze potwierdzony jest już 11 marca 1372 r. ${ }^{10}$. W dokumencie Streczka zaświadcza, że siostra

${ }^{6}$ Urkunden der Stadt Brieg. Urkundliche und chronikalische Nachrichten über die Stadt Brieg, die dortigen Klöster, die Stadt- und Stiftsgüter bis zum Jahre 1550, wyd. C. Grünhagen, Breslau 1870, Codex diplomaticus Silesiae, t. 9 [dalej: CDS 9], nr 253, s. 37.

7 Opis pieczęci konwentu raciborskich dominikanek, zob. Urkunden der Klöster Rauden und Himmelwitz, der Dominicaner und der Dominicanerinnen in der Stadt Ratibor, wyd. W. Wattenbach, Breslau 1859, Codex diplomaticus Silesiae, t. 2 [dalej: CDS 2], s. 179.

${ }^{8}$ Opis pieczęci miasta Brzegu, zob. CDS 9, s. 280-285.

${ }^{9}$ G. K u b 1 i n, Eufemia raciborska - priorissa, ,Studia Teologiczno-Historyczne Śląska Opolskiego" t. 32, 2012, s. 287-294.

${ }^{10}$ CDS 2, nr 59, 62, 69, s. 165, 169, 176; A. B a r c i a k, Eufemia, księżniczka opawskoraciborska, dominikanka raciborska $w$ drugiej połowie XIV wieku, [w:] Scriptura, 
Agnieszka ustanowiła głubczyckiego komtura Witka z Żor i rybnickiego plebana Wawrzyńca opiekunami i pełnomocnikami we wszystkich czynnościach prawnych odnośnie do jej rocznego czynszu 10 grzywien $\mathrm{z}$ dochodów miasta Brzegu. Ten czynsz został zapisany Agnieszce w testamencie jej nieżyjącego ojca Konrada Sleussera (Cunadus Sleusserius), mieszkańca Nysy. Tenże Konrad (Chunato dictus Slüsser de Nysa; Cunadus dictus Slewser ciuis de Nisa) wystąpił wcześniej jako świadek w dokumencie księcia opawsko-raciborskiego Mikołaja II Przemyślidy, wydanym 22 sierpnia 1340 r., w którym wspomniany władca potwierdził klasztorowi dominikanek w Raciborzu nabycie Baborowa, Sułkowa, Czerwonkowa i Dzielowa ${ }^{11}$. Być może jest on tożsamy z Konradem Sleusserem, mieszkańcem Wrocławia, który w 1338 r. otrzymał zakaz handlu we Wrocławiu, wydany przez radę tegoż miasta z powodu jakiegoś naruszenia prawa ${ }^{12}$.

Ustanowieni pełnomocnicy Agnieszki nie wzbudzają podejrzeń. Pierwszy z nich, Witko z Żor, występuje w źródłach jako joannicki komtur głubczycki nie tylko w przedstawianym dokumencie Streszki z 29 sierpnia 1365 r., lecz także był obecny na zebraniu joannickich komturów 7 lutego 1378 r. w Kłodzku ${ }^{13}$. Dnia 4 lipca 1369 r. wystąpił w Otmuchowie jako komtur w Makowie (Witkone de Zarow crucifero comendatore in Macow) ${ }^{14}$. Drugi z nich, Wawrzyniec był plebanem w Rybniku. Wystąpił 8 czerwca 1343 r. jako świadek transumptu sporządzonego na polecenie przeoryszy raciborskich dominikanek Eufemii, córki księcia raciborskiego Przemysła ${ }^{15}$. Na rzecz jego, jako ple-

diploma, sigillum, red. J. Zdrenka, J. K a r c zew s k a, Zielona Góra 2009, s. 303-308.

${ }^{11}$ CDS 2, nr 36, 37, s. 143, 146.

12 Regesten zur schlesischen Geschichte 1338-1342, t. 8, wyd. K. Wutke, E. Randt, Breslau 1925, Codex diplomaticus Silesiae, t. 30, nr 6024, s. 1.

13 CDS 9, nr 253, 405, s. 37, 58; A. Weltzel, Besiedelungen des nördlich der Oppa gelegenen Landes, t. 2, Ratibor 1891, s. 121; R. Heś, Joannici na Śląsku w średniowieczu, Kraków 2017, s. 479. Niektórzy przyjmują, że był komturem w Głubczycach w latach 1365-1378, zob. M. S t a r n a w s k a, Między Jerozolima a Łukowem. Zakony krzyżowe na ziemiach polskich $w$ średniowieczu, Warszawa 1999, s. 45, 353; K. Maler, Joannici $w$ Gtubczycach $i$ Grobnikach i ich komturowie, „Kalendarz Głubczycki” t. 15, 2008, s. 126.

14 Archiwum Państwowe we Wrocławiu, Rep. 111, nr 7; A. W e 1 t z e 1, Geschichte des Ratiborer Archipresbyterats, Breslau 1896, s. 247; R. He ś, Joannici na Ślasku, dz. cyt., s. 493.

${ }^{15}$ CDS 2, nr 40, s. 149. 
bana rybnickiego, i jego następców poczyniono darowizny w $1356 \mathrm{r}$. i 8 maja 1357 r. $^{16}$. W końcu pojawił się $\mathrm{w}$ dokumencie przeoryszy Streczki z 29 sierpnia 1365 r. $^{17}$.

Natomiast biskup wrocławski Przecław, sprawujący swój urząd w latach 1342-1376, potwierdził 13 stycznia 1366 r., że w jego obecności spadkobiercy Konrada Sleussera (Cunradus Slusser), zmarłego mieszkańca Nysy, uzgodnili, iż powinni przekazać Agnieszce, córce wspomnianego zmarłego, zakonnicy w Raciborzu, roczny czynsz 10 grzywien z dochodów miasta Brzegu, który za życia nabył jej ojciec. W tym dokumencie Agnieszka została określona jako zakonnica (sanctimonialis), która złożyła śluby (professa) w Raciborzu. Skopiowana treść dokumentu została poprzedzona tytułem: Copia litterae Agnetis monialis in Rathibor. Pod tekstem umieszczono informację, że pieczęć jest zawieszona (Sig[illum] pendulum).

Oba przedstawiane XIV-wieczne dokumenty stanowią cenne źródło do dziejów klasztoru dominikanek w Raciborzu. Z nich poznajemy raciborską przeoryszę Streczkę i siostrę zakonną Agnieszkę, córkę Konrada Sluessera, mieszkańca Nysy. Zważywszy na wciąż niezadawalającą ilość średniowiecznych dyplomów dotyczących Górnego Śląska, w pełni zasługują one na opublikowanie.

${ }^{16}$ L. M u s i o 1, Parafia Matki Boskiej Bolesnej w Rybniku. Monografia historyczna, bm. 1970, mps w Bibliotece Śląskiej w Katowicach, sygn. R 866 III, s. 36, 61; J. S perka, Do 1532 roku, [w:] Rybnik. Dzieje miasta i jego dzielnic, t. 1, red. Z. H oj k a, B. K 1 o c h, Rybnik 2017, s. 196.

${ }^{17}$ CDS 9, nr 253, s. 37; A. B a r c i a k, Sacrum a średniowieczny Rybnik, [w:] Sacrum i profanum. Klasztory $i$ miasta $w$ rzeczywistości Górnego Śląska w średniowieczu, red. E. B im le r-M a cki ew ic z, Rybnik 2003, s. 85; Regesty dokumentów przechowywanych na Górnym Śląsku, t. 1, dz. cyt., nr 86, s. 51. 


\section{ANEKS}

Przy opracowaniu treści pierwszego dokumentu do druku posłużono się wskazaniami Adama Wolffa ${ }^{18}$ i wydawców nowej edycji Kodeksu dyplomatycznego Wielkopolskiego ${ }^{19}$. Ponieważ podstawę wydania drugiego dokumentu stanowiła kopia zapewne z XIX w., dlatego pisownia w nim wcześniej uległa modernizacji (np. bonae memoriae - zamiast bone memorie) i zastosowano Instrukcję Kazimierza Lepszego ${ }^{20}$.

\section{I}

Racibórz, 29 sierpnia 1365 r.

„Streczka, przeorysza klasztoru dominikanek w Raciborzu, zaświadcza, że siostra zakonna Agnieszka ustanowiła głubczyckiego komtura Witka z Żor i rybnickiego plebana Wawrzyńca opiekunami i pełnomocnikami we wszystkich czynnościach prawnych odnośnie do jej rocznego czynszu 10 grzywien z dochodów miasta Brzegu, zapisanego tejże Agnieszce w testamencie jej nieżyjącego ojca Konrada Sleussera, mieszkańca Nysy".

Oryginał: Archiwum Państwowe w Opolu, zespół 1242: Akta miasta Brzegu, nr 8309.

Kopia: nieznana.

Regesty: CDS 9, nr 253, s. 37; Regesty dokumentów przechowywanych na Górnym Śląsku, t. 1, dz. cyt., nr 86, s. 51.

Wzmianka: A. Weltzel, Geschichte der Stadt und Herrschaft Ratibor, Ratibor 1881, s. 822.

Ego soror Streczka, miseratione divina priorissa monasterii Sancti Spiritus in Rathibor, et universitas seu communitas sororum monas-

18 A. W olf f, Projekt instrukcji wydawniczej dla pisanych źródeł historycznych do połowy XVI wieku, [w:] J. T a ndecki, K. K o piński, Edytorstwo źródel historycznych, Warszawa 2014, s. 328-354.

19 Kodeks dyplomatyczny Wielkopolski, t. 6, wyd. A. Gą s i o row s ki, H. K ow a le w i c z, Warszawa-Poznań 1982, s. XIII-XVIII.

${ }^{20} \mathrm{~K}$. L e p s z y, Instrukcja wydawnicza dla źródel historycznych od XVI do połowy XIX wieku, [Wrocław 1953], [w:] J. T a n d e c k i, K. K o p i ń s k i, Edytorstwo źródet historycznych, dz. cyt., s. 359-384. 
terii eiusdem sub regula et obedientia fratrum Predicatorum viva voce unanimes insimul perficemur publice omnibus et singulis hanc paginam legentibus vel audientibus, quod de speciali licentia de consensu omnium sororum et matura deliberatione prehabita, soror Agnes olim nata Cunadi Sleusserii civis in Nyssa fecit, constituit et ordinavit honorabiles viros dominos Wytkonem de Zarow commendatorem in Lubschicz et Laurentium plebanum in Rybnik suos procuratores legitimos et nuntios speciales in universis negotiis ipsius ad eam spectantes ex parte testamenti facti eidem, $\mathrm{X}$ videlicet marcarum reddituum census annualis in civitate Bregensi super dominos consules et universitatem civitatis eiusdem, quousque ab eadem civitate centum marcas grossorum Pragensium Polonicalis numeri rehabere valeret cum censo nondum persoluto. Simili modo de portione paterna ipsam hereditarie contingentem quidquid per ipsos Wytkonem de Zarow et Laurentium de Rybnik tractatum compositum, ordinatum seu amicabiliter concordatum extiteret, hoc ipsa Agnes wlt habere gratum, ratum et acceptum. Nos vero ad instantiam eius ex caritate sincera omnia et singula, que facta et ordinata per prefatos procuratores faciantur, ex parte sororis nostre Agnetis prenotate promittimus tenere sine omni contradictione et perpetuis temporibus inviolabiliter observare. In cuius rei evidenciam presentem cartulam sigillo conventus nostri duximus roborandam. Datum Rathibor in Decollatione sancti Johannis Baptiste [29 VIII] anno Domini $\mathrm{M}^{\circ} \mathrm{CCC}^{\circ} \mathrm{LX}^{\circ}$ quinto.

\section{II}

Otmuchów, 13 stycznia $1366 \mathrm{r}$.

„Przecław, biskup wrocławski, potwierdza, że w jego obecności spadkobiercy Konrada Sleussera, zmarłego mieszkańca Nysy, uzgodnili, iż powinni dać i przekazać Agnieszce, córce wspomnianego zmarłego, zakonnicy w Raciborzu, roczny czynsz 10 grzywien z dochodów miasta Brzegu, który za życia nabył jej ojciec".

Oryginał: nieznany.

Kopia: Archiwum Państwowe w Opolu, zespół 1242: Akta miasta Brzegu, nr 14. 
Regest: Regesty dokumentów przechowywanych na Górnym Ślasku, t. $1, d z$. cyt., nr 89, s. 52 .

Nos Preczlaus, Dei gratia episcopus Wratislaviensis, recognoscimus tenore praesentium universis, quod constitutis in nostra praesentia haeredibus bonae memoriae Cunradi dicti Slusser ${ }^{21}$, quondam civis sive oppidani nostri Nissensis, et cohaeredibus religiosae Agnethis, sanctimonialis professae monasterii sanctimonialium in Rathibor, filiae Cunradi Slusser praetacti, unanimiter consenserunt, quod littera sive litterae super reditibus decem marcarum annuis, quos praetactus Cunradus Slusser in et super oppido Bregensi dum viveret obtinebat, dari et tradi deberent liberae Agneti praedictae, occasione portionis ipsam Agnetem in bonis eiusdem sui patris quolibet contigente. Harum quibus nostrum sigillum appensimus et testimonio literarum. Datum Othmuchow, Idus Januarii [13 I] anno Domini 1366.

${ }^{21}$ W kopii: Sluser. To raczej błąd XIX-wiecznego kopisty, gdyż dalej w tym samym zdaniu występuje: Slusser. 


\section{Bibliografia}

\section{Źródła archiwalne}

Archiwum Państwowe w Opolu, zespół 1242: Akta miasta Brzegu, nr 14, 8309. Archiwum Państwowe we Wrocławiu, Rep. 111: Ratibor, Kollegiatstift ad s. Thomam, $\mathrm{nr} 7$.

\section{Źródła drukowane}

Breslauer Urkundenbuch, wyd. G. Korn, Breslau 1870.

Kodeks dyplomatyczny Wielkopolski, t. 6, wyd. A. Gąsiorowski, H. Kowalewicz, Warszawa-Poznań 1982.

Regesten zur schlesischen Geschichte 1327-1333, t. 6, wyd. C. Grünhagen,

K. Wutke, Breslau 1903, Codex diplomaticus Silesiae, t. 22.

Regesten zur schlesischen Geschichte 1334-1337, t. 7, wyd. K. Wutke, Breslau 1923, Codex diplomaticus Silesiae, t. 29.

Regesten zur schlesischen Geschichte 1338-1342, t. 8, wyd. K. Wutke, E. Randt, Breslau 1925, Codex diplomaticus Silesiae, t. 30.

Regesty dokumentów przechowywanych na Górnym Ślasku, t. 1, red. A. Barciak, K. Müller, Wrocław-Opava 2004.

Urkunden der Klöster Rauden und Himmelwitz, der Dominicaner und der Dominicanerinnen in der Stadt Ratibor, wyd. W. Wattenbach, Breslau 1859, Codex diplomaticus Silesiae, t. 2.

Urkunden der Stadt Brieg. Urkundliche und chronikalische Nachrichten über die Stadt Brieg, die dortigen Klöster, die Stadt- und Stiftsgüter bis zum Jahre 1550, wyd. C. Grünhagen, Breslau 1870, Codex diplomaticus Silesiae, t. 9.

\section{Literatura}

Barciak A., Eufemia, księżniczka opawsko-raciborska, dominikanka raciborskg $w$ drugiej połowie XIV wieku, [w:] Scriptura, diploma, sigillum, red. J. Zdrenka, J. Karczewska, Zielona Góra 2009, s. 303-308.

Barciak A., Sacrum a średniowieczny Rybnik, [w:] Sacrum i profanum. Klasztory $i$ miasta $w$ rzeczywistości Górnego Ślaska $w$ średniowieczu, red. E. Bimler-Mackiewicz, Rybnik 2003, s. 81-87.

Barciak A., Skład osobowy klasztoru dominikanek raciborskich w średniowieczu, [w:] Sanctimoniales. Zakony żeńskie w Polsce i Europie Środkowej (do przełomu XVIII $i$ XIX wieku), red. A. Radzimiński, D. Karczewski, Z. Zyglewski, Bydgoszcz-Toruń 2010, s. 333-341.

Heś R., Joannici na Ślasku w średniowieczu, Kraków 2017.

Kaczmarek K., Przyczynek do badań nad prozopografia konwentu dominikanek wroctawskich w średniowieczu, [w:] Sanctimoniales. Zakony żeńskie w Polsce 
i Europie Środkowej (do przełomu XVIII i XIX wieku), red. A. Radzimiński, D. Karczewski, Z. Zyglewski, Bydgoszcz-Torun 2010, s. 342-352.

Kłoczowski J., Dominikanie polscy na Ślasku w XIII-XIV wieku, Lublin 1956. Kublin G., Dzieło Reginalda Brauna z 1741 roku poświęcone księżniczce raciborskiej Eufemii, Opole 2018, Studia i źródła do dziejów dominikanów i dominikanek w Raciborzu, t. 2.

Kublin G., Eufemia raciborska - priorissa, ,Studia Teologiczno-Historyczne Śląska Opolskiego" t. 32, 2012, s. 287-294.

Kublin G., Średniowieczne $i$ nowożytne testimonia sanctitatis Eufemii raciborskiej (zm. 1359), „Folia Historica Cracoviensia” t. 19, 2013, s. 73-90. Kublin G., Świątobliwa Eufemia raciborska (†17 I 1359), Opole 2013.

Kublin G., XVII-wieczny żywot księżniczki raciborskiej Eufemii w zbiorach Archiwum Państwowego we Wrocławiu, Opole 2016, Studia i źródła do dziejów dominikanów i dominikanek w Raciborzu, t. 1 .

Lepszy K., Instrukcja wydawnicza dla źródet historycznych od XVI do polowy XIX wieku, [Wrocław 1953], [w:] J. Tandecki, K. Kopiński, Edytorstwo źródet historycznych, Warszawa 2014, s. 359-384.

Maler K., Joannici $w$ Gtubczycach $i$ Grobnikach $i$ ich komturowie, „Kalendarz Głubczycki” t. 15, 2008, s. 124-137.

Musioł L., Parafia Matki Boskiej Bolesnej w Rybniku. Monografia historyczna, bm. 1970, mps w Bibliotece Śląskiej w Katowicach, sygn. R 866 III.

Sperka J., Do 1532 roku, [w:] Rybnik. Dzieje miasta i jego dzielnic, t. 1, red. Z. Hojka, B. Kloch, Rybnik 2017, s. 135-203.

Starnawska M., Między Jerozolima a Łukowem. Zakony krzyżowe na ziemiach polskich w'średniowieczu, Warszawa 1999.

Stefaniak P., Błogosławiona Eufemia Piastówna OP (1299-1359) w świetle trzech najstarszych żywotów oraz źródel a także literatury, „Nasza Przeszłość" t. 111, 2009, s. 159-191.

Stefaniak P., Najstarszy polski klasztor dominikanek klauzurowych i jego mieszkanki, „Kronika Miasta Poznania” t. 3, 2004, s. 120-130.

Stefaniak P., Z dziejów klasztoru Świętego Ducha mniszek dominikańskich w Raciborzu (1299-1810), „Nasza Przeszłość” t. 112, 2009, s. 181-206.

Suchoń B., Ofka, Eufemia, Domitilla, [w:] Hagiografia Polska. Słownik bio-bibliograficzny, t. 2, red. R. Gustaw, Poznań 1972, s. 160-171.

Tarnas-Tomczyk A., Uposażenie fundacyjne śląskich klasztorów żeńskich do połowy XIV wieku, [w:] Sanctimoniales. Zakony żeńskie w Polsce i Europie Środkowej (do przełomu XVIII i XIX wieku), red. A. Radzimiński, D. Karczewski, Z. Zyglewski, Bydgoszcz-Toruń 2010, s. 206-233.

Weltzel A., Besiedelungen des nördlich der Oppa gelegenen Landes, t. 2, Ratibor 1891.

Weltzel A., Geschichte des Ratiborer Archipresbyterats, Breslau 1896. 
Wolff A., Projekt instrukcji wydawniczej dla pisanych źródeł historycznych do połowy XVI wieku, [w:] J. Tandecki, K. Kopiński, Edytorstwo źródet historycznych, Warszawa 2014, s. 328-354.

Wolnik F., Świątobliwa Eufemia (Ofka) - życie i rozwój jej kultu, [w:] Świętość na ziemi raciborskiej, red. Tenże, Opole 2009, Sympozja, t. 76, s. 23-43.

KS. GRZEGORZ KUBLIN

\title{
DWA NIEDRUKOWANE DOKUMENTY DOTYCZĄCE RACIBORSKIEJ DOMINIKANKI AGNIESZKI
}

Streszczenie: W Archiwum Państwowym w Opolu, w zespole Akta miasta Brzegu, przechowywane są dwa dokumenty dotyczące raciborskiej dominikanki Agnieszki, profeski, córki rzemieślnika Konrada Sleussera z Nysy. Są one znane jedynie z regestów. Pierwszy z nich (sygn. 8309) został wystawiony 29 sierpnia 1365 r. i zachował się w oryginale. Drugi dokument (sygn. 14) pochodzi z 13 stycznia 1366 r. i funkcjonuje jedynie jako papierowa kopia, sporządzona zapewne w XIX w. Oba nie zostały dotąd wydane drukiem.

Słowa kluczowe: Agnieszka z Nysy, biskup Przecław, dominikanki, raciborskie dominikanki, Racibórz, Streczka.

\section{TWO UNPRINTED DOCUMENTS CONCERNING AGNES, A DOMINICAN NUN FROM RACIBÓRZ}

\begin{abstract}
In the State Archives of Opole, in the Files of the City of Brzeg, there are two documents regarding Agnes, a Dominican professed nun, daughter of craftsman Konrad Sleusser from Nysa. The documents are only known from regesta. The first one (RF 8309) was issued on August 29, 1365 and has been preserved in the original. The second one (RF 14) dates from January 13, 1366 and functions only as a paper copy, probably made in the $19^{\text {th }}$ century. Both have not yet been printed.
\end{abstract}

Keywords: Agnes from Nysa, bishop Przecław, Dominican nuns, Dominican nuns from Racibórz, Racibórz, Streczka. 
